\title{
Guión Teatralizado en el Museo del Carmen Alto
}

\author{
Theatrical script in the Museum of CARMen Alto
}

Ph.D. Jesús Francisco González Alonso Universidad Tecnológica Israel - Ecuador jesusgalonso@uisrael.edu.ec

María Belén Almeida Egas Empresa Mixta Refinería del Pacífico mabe_mb@hotmail.com

Fecha de recepción: 08/05/2016 Fecha de Aceptación: 11/06/2016

\begin{abstract}
Resumen
Este trabajo pretende demostrar la importancia del uso de herramientas comunicativas y educacionales en los museos. Estos espacios deben ser lugares de educación de masas y no exactamente instituciones que se dediquen a la recolección de objetos.

Desde hace algún tiempo en algunos países de Latino América y en especial en Ecuador se maneja la guianza en museos de manera formal, siendo así el guía el único poseedor de la verdad. De esta manera que se puede confirmar que el visitante percibe el conocimiento de forma directa y los museos mantienen su enfoque tradicional con el conocido lema: "Ver y No tocar".
\end{abstract}


Para incrementar el turismo religioso en el Monasterio del Carmen de San José se ha propuesto el desarrollo de un guión teatralizado como servicio de interacción en base de herramientas investigativas con la finalidad de dar valor al patrimonio religioso albergado por este monasterio por más de 360 años.

Palabras clave: Patrimonio, monasterios, museos, turismo religioso, herramientas educativas.

\section{Abstract}

This paper aims to show the importance of using communication and educational tools in museums, these spaces should be places of mass education and not just institutions dedicated to collecting objects. Since some time ago in some countries in Latin America and especially in Ecuador, the guidance is handled formally in museums showing that the tour guide is the only person how has the knowledge, It is in this way that you can confirm the public perceives knowledge directly and museums keep their traditional approach to the known slogan: "See and not touch ".

In order to increase the religious tourism in the "Monastery de San José" has been proposed the development as a theatrical script based in the interaction service tool investigated in order to give value to the religious heritage hosted by the monastery for over 360 years.

Key words: Patrimony, monasteries, museums, religious tourism, educational tools. 


\section{Introducción}

El museo del Carmen Alto se encuentra situado en las calles García Moreno y Rocafuerte en la ciudad de Quito, el Monasterio del Carmen de San José decidió crear un museo para que el turismo religioso se pueda incrementar en la ciudad capital del Ecuador, abrió sus puertas el 4 de diciembre del 2013. Es importante recalcar que este monasterio fue el primero de los Carmelitas en abrirse en la época de la Real Audiencia de Quito y fue fundado en la casa de Santa Mariana de Jesús que es conocida como la "Azucena de Quito".

En este museo se puede apreciar el patrimonio religioso albergado por las hermanas Carmelitas por más de trescientos sesenta años y pretende fomentar la apropiación del valor tangible e intangible.

La exposición temporal está basada en la tradición oral de las hermanas y los ejes del museo son: la vida cotidiana de la Orden Carmelita, la historia de la Santa Mariana de Jesús y el arte religioso en el monasterio. El turismo religioso no tiene por qué ser aburrido y debería ser valorado como parte de la cultura de cualquier pueblo.

Kennedy, Alexandra (2002) dice que "Las monjas, provenientes mayoritariamente de los sectores de poder, y las mujeres que vivían en los claustros como recogidas, donadas, sirvientas libres o negras esclavas, conformaron una población multiétnica , multirracial y multi-social, capaz de ejercer roles diversos y complementarios con mecenas, artistas, artesanas, "restauradoras" y "mantenedoras" de un arte y acciones artísticas aun poco valoradas (...)En Ecuador sobre sale la presencia de las órdenes concepcionista desde fines del siglo XVI y carmelita desde mediados del centuria siguiente. La primera, de fundación regia, tuvo una destacada presencia en toda la América Hispana. En tanto que la carmelita tuvo especial significación en esta región debido a que varios familiares de Santa Teresa de Jesús de Ávila pasaron por Quito”.

El patrimonio religioso es tan poco apreciado por los ecuatorianos ya lo dijo González Suárez en el prólogo de su libro Historia General de la República del Ecuador "Hay en Ecuador decía tan poco aprecio por las obras nacionales, que no solo sin dificultad, sino con gusto se apresuran nuestras gentes a regalar o vender a los extranjeros los objetos de arte antiguo que debían estar custodiados en un museo nacional. Museo nacional de antigüedades ecuatorianas! Parece que nunca lo hemos de tener, según se presenta la marcha de la vida social en nuestra República". 
En nuestro trabajo nos propusimos como pregunta para el desarrollo de la investigación ¿De Qué manera se puede desarrollar un guión teatralizado en el museo del Carmen Alto para de esta forma aportar a que los recorridos sean más interactivos, y que pueda existir la retroacción, motivando al visitante a interactuar con los personajes a desarrollarse? Y para dar su cumplimiento el objetivo está dirigido al análisis del uso de la representación como instrumento de reconstrucciones de experiencias encarnadas para avanzar en la comprensión del acervo cultural del museo basada en palabras.

\section{Interrelación de los museos y el sistema educativo}

Los museos y el sistema educativo mantienen una estrecha relación con la educación formal. De esta manera el guía en el museo y el profesor en el aula actúan como legisladores, siendo los únicos conocedores de la verdad. A diferencia del guía turístico, el profesor puede evaluar de qué manera le llega el conocimiento al estudiante por medio de lecciones, actividades, comprobaciones, etc. Pero el guía turístico nunca sabe a ciencia cierta de que manera fue adquirido el mensaje proporcionado en el recorrido, es importante resaltar, que para la psicología existen tres tipos de educación que son: formal, no formal e informal.

El total de visitantes potenciales debería ser considerado como "público objetivo" ya que para que funcione un museo, se debe delimitar en qué grupo pueden llegar a ser insertados y de esta manera definir el propósito de la visita al museo.

Verdecchia (2003) contempla diferentes variables para diseñar estrategias en el área y manejo para mejorar el producto en los museos, estos son:

1. Cognitiva (qué conoce el visitante del área)

2. Valoración (criterios de conservación, motivo de la visita, importancia asignada al área, grado de satisfacción)

3. Actividades (qué realiza el visitante en el área, modalidad de visita, procedencia, frecuencia, duración)

4. Preferencias (que le gustó más y qué menos, expectativas, evaluación de servicios)

5. Tipología (características del visitante, perfil)

6. Gestión (sugerencias de manejo)

\section{Herramientas educativas aplicadas a las enseñanzas en los museos}

\section{Teorías del aprendizaje}

Piaget, Jean (2003) comenzó a estudiar el desarrollo de la educación a principios del siglo XX y hasta este tiempo se sigue aprobando sus teorías constructivistas. Su teoría está basada en un enfoque holístico que postula que el niño adquiere el conocimiento a través de diversos canales como la exploración, la música, 
el medio ambiente, la lectura, el escucha, siempre con observación y su experimentación en base a las sensaciones obtenidas.

\section{Constructivismo en el museo}

La educación se vuelve interdisciplinaria cuando se demuestra que hay construcción individual de propios conceptos; "Un componente fundamental debería ser la posibilidad de permitir que el visitante haga primero conexiones con conceptos y objetos familiares; para dar significado a nuestra experiencia necesitamos ser capaces de conectarla con lo que ya conocemos. Las exposiciones constructivistas deben estimular igualmente comparaciones entre lo nuevo y lo desconocido así como con procesos y elementos transdisciplinarios" Rubiales (2003).

El papel del mediador debería ser como un animador que proponga para que se adquiera el conocimiento mediante análisis, preguntas y respuestas, ósea con una interacción durante todo el recorrido.

\section{Teoría conductual del aprendizaje}

Esta teoría se basa en las teorías de Pavlov, Iván (2003) se centra en el estudio de la conducta observable para contralar y lograr una conducta determinada. Se podrá obtener una respuesta deseada si se sabe plantear los estímulos adecuados y así se describirá una asociación entre un estímulo y su respuesta.

Teoría cognitiva del aprendizaje.

Los procesos involucrados en el manejo de la información por parte del visitante en el caso del museo son en este caso la percepción, atención, memoria, la capacidad de razonamiento, es decir esta teoría se basa en la adaptación de lo aprendido con la vida diaria. Se afirma también que la relación es estrecha entre el medio ambiente y el ser humano.

\section{Teoría del aprendizaje mediado}

A partir de los estímulos viene el aprendizaje, este consiste en la transformación de un estímulo emitido por el medio a través del mediador, sea profesores, padres, o en el caso guías turísticos el cual la persona lo procesa para crear conocimientos. El papel del mediador es crear un tipo de estado de curiosidad o alerta mediante estímulos con el fin de que el visitante adquiera conocimiento. Pavlov, Iván (2003)

Teoría humanista del aprendizaje.

"La teoría humanista nació como un movimiento de protesta. Maslow planteó que los movimientos psicológicos estaban centrados en la enfermedad y la deficiencia, y creía que la psicología se beneficiaría si se concen- 
traba en el estudio de las personas sanas" (Ríos, 2005). El guía mediador debe motivar al público visitante a que dejen de actuar como entes pasivos y que puedan participar en los recorridos con conversaciones extensas y que pueda existir la interrelación. La educación no formal es un aporte que puede ser donada por los museos para todo público, porque estos tienen la misión de estimular los procesos imaginativos y de transformación y así crear lasos de identidad.

\section{Ejes temáticos del Museo del Carmen Alto}

\section{Mapa Museológico}

En la investigación que se realizó previamente a la apertura del museo en la fase curatorial, se recopilaron testimonios de tradición oral de las religiosas y junto al equipo técnico de la Fundación Museos de la Ciudad, se distribuyó los espacios, el montaje de las obras, la señalética y el cedulario. Pavlov, Iván (2003)

Las plantas del museo están distribuidas de la siguiente manera:

Figura No. 1 Vista de la primera planta del Museo del Carmen Alto

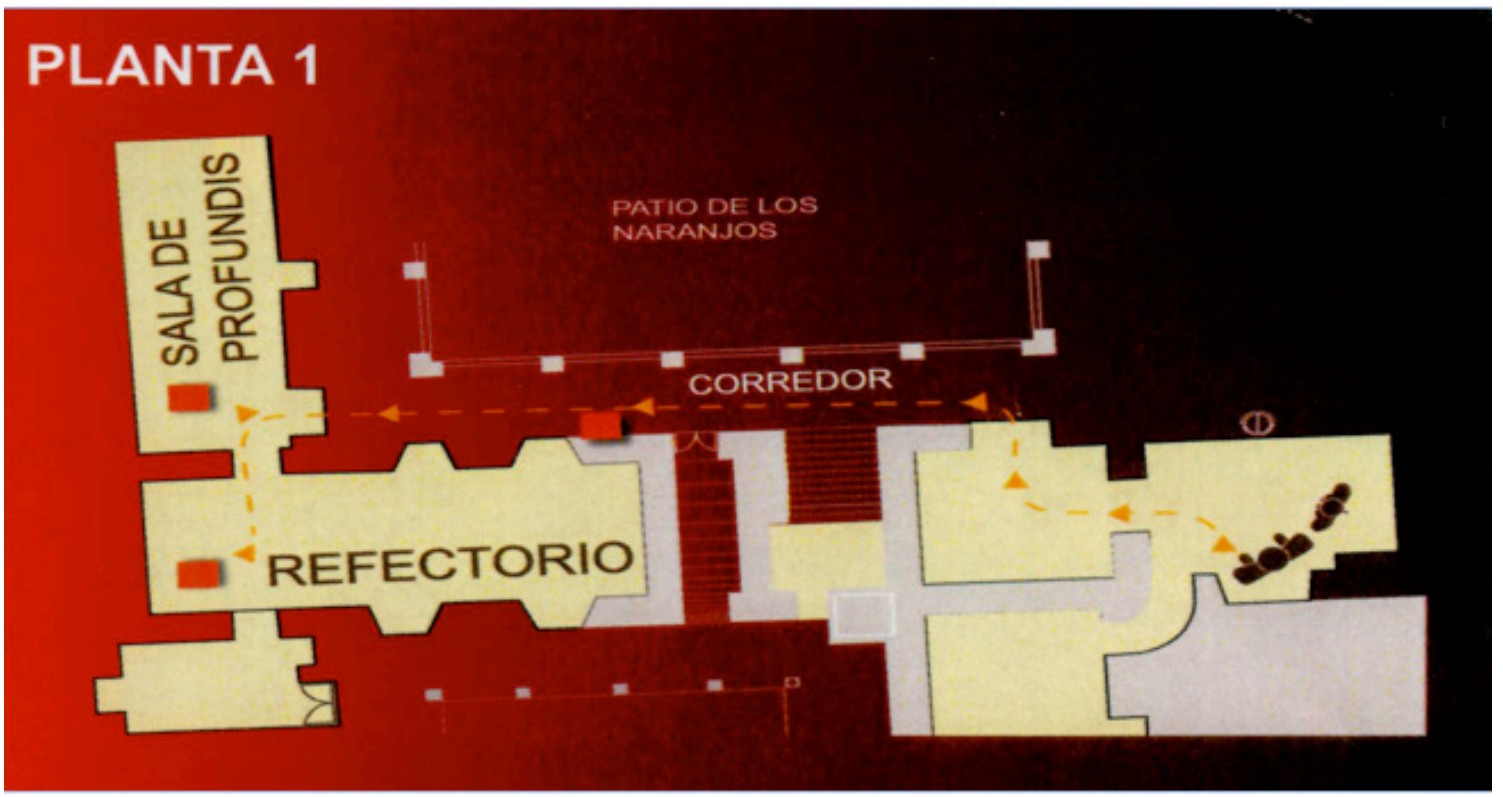

Fuente: Guía del Museo del Carmen Alto, http://es.scribd.com/doc/189535482/GUIA-DEL-MUSEO-DEL-CARMEN-ALTO\#scribd 
Figura No. 2 Vista de la segunda planta del Museo del Carmen Alto.

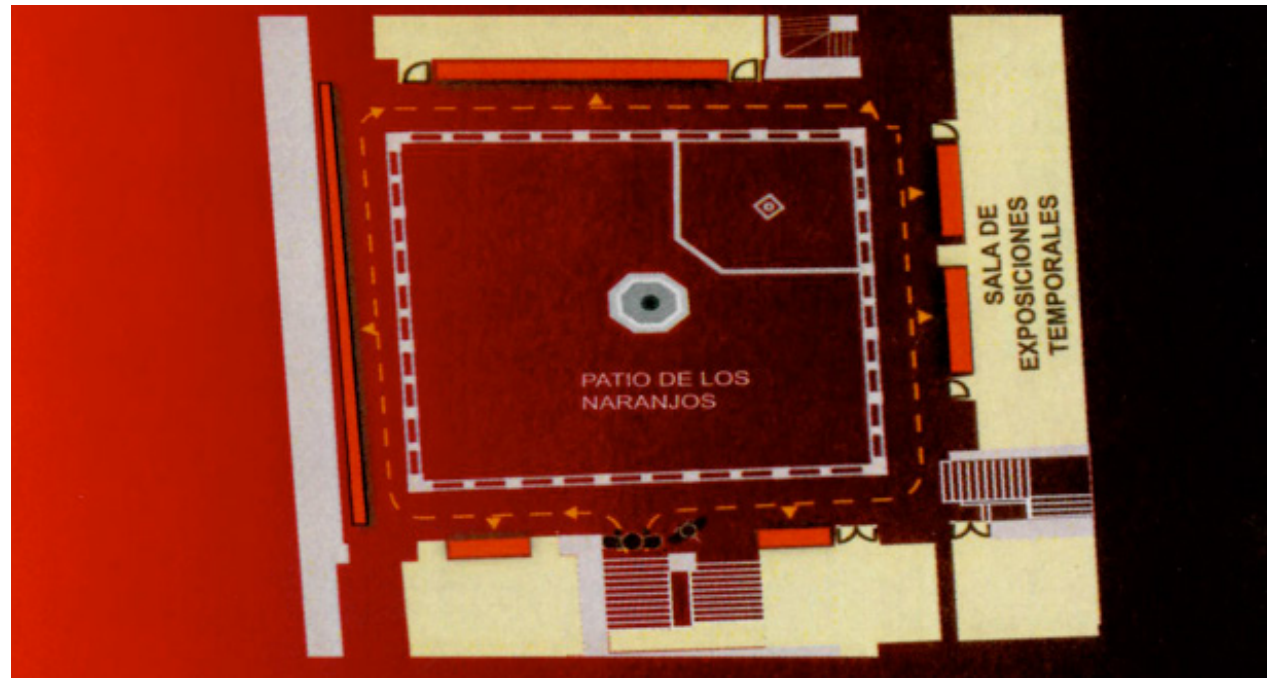

Fuente: Guía del Museo del Carmen Alto,

http://es.scribd.com/doc/189535482/GUIA-DEL-MUSEO-DEL-CARMEN-ALTO\#scribd

Figura No. 3 Vista de la tercera planta del Museo del Carmen Alto

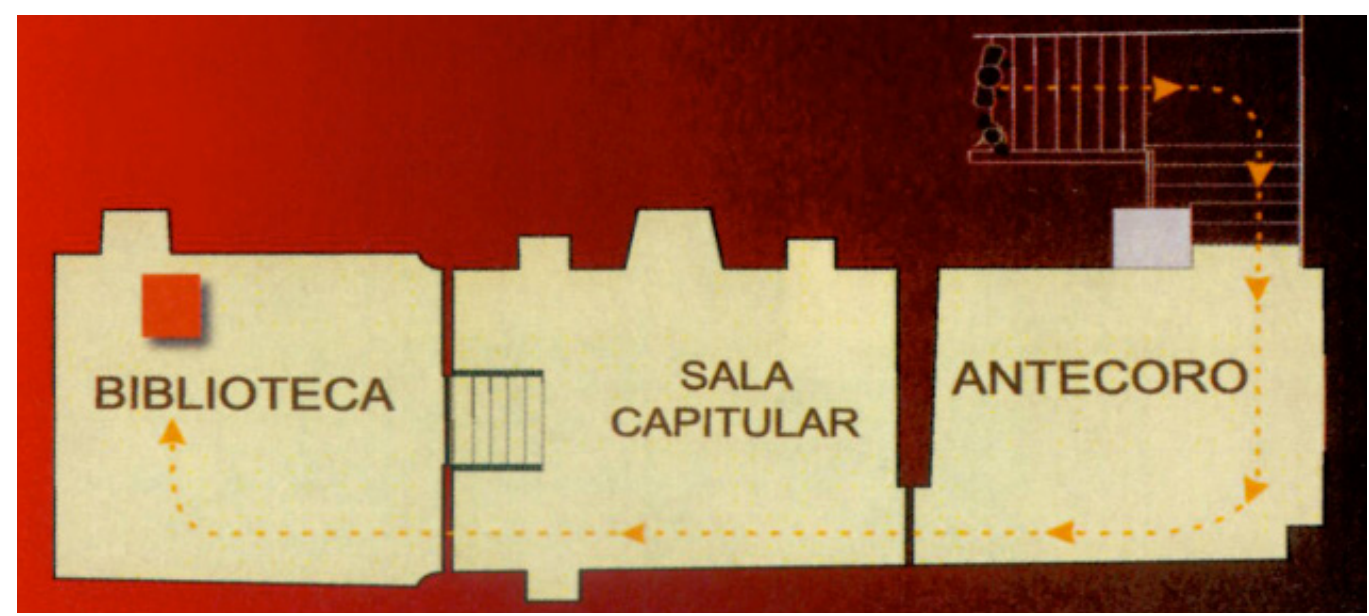

Fuente: Guía del Museo del Carmen Alto,

http://es.scribd.com/doc/189535482/GUIA-DEL-MUSEO-DEL-CARMEN-ALTO\#scribd 


\section{El legado artístico del monasterio}

El claustro es de estilo clásico formado por arcos de medio punto, construidos sobre pilastras de planta cuadrada en la planta baja. "Mariana de Jesús hizo una profecía detallando la ubicación de las dependencias del monasterio carmelitano en su casa, la cumplió, sin darse cuenta, el Hermano Marcos Guerra de la Compañía de Jesús... trazó los planos de la iglesia en dirección de la llamada Calle Larga; y al fondo los tramos interiores del convento, con jardines y con huerto" (Larrea, 1974).

Hoy el museo cuenta con 2596 bienes pero alrededor de 1500 se encuentran en exposición.

Figura No. 4 Dormición de la Virgen María, Museo del Carmen Alto.

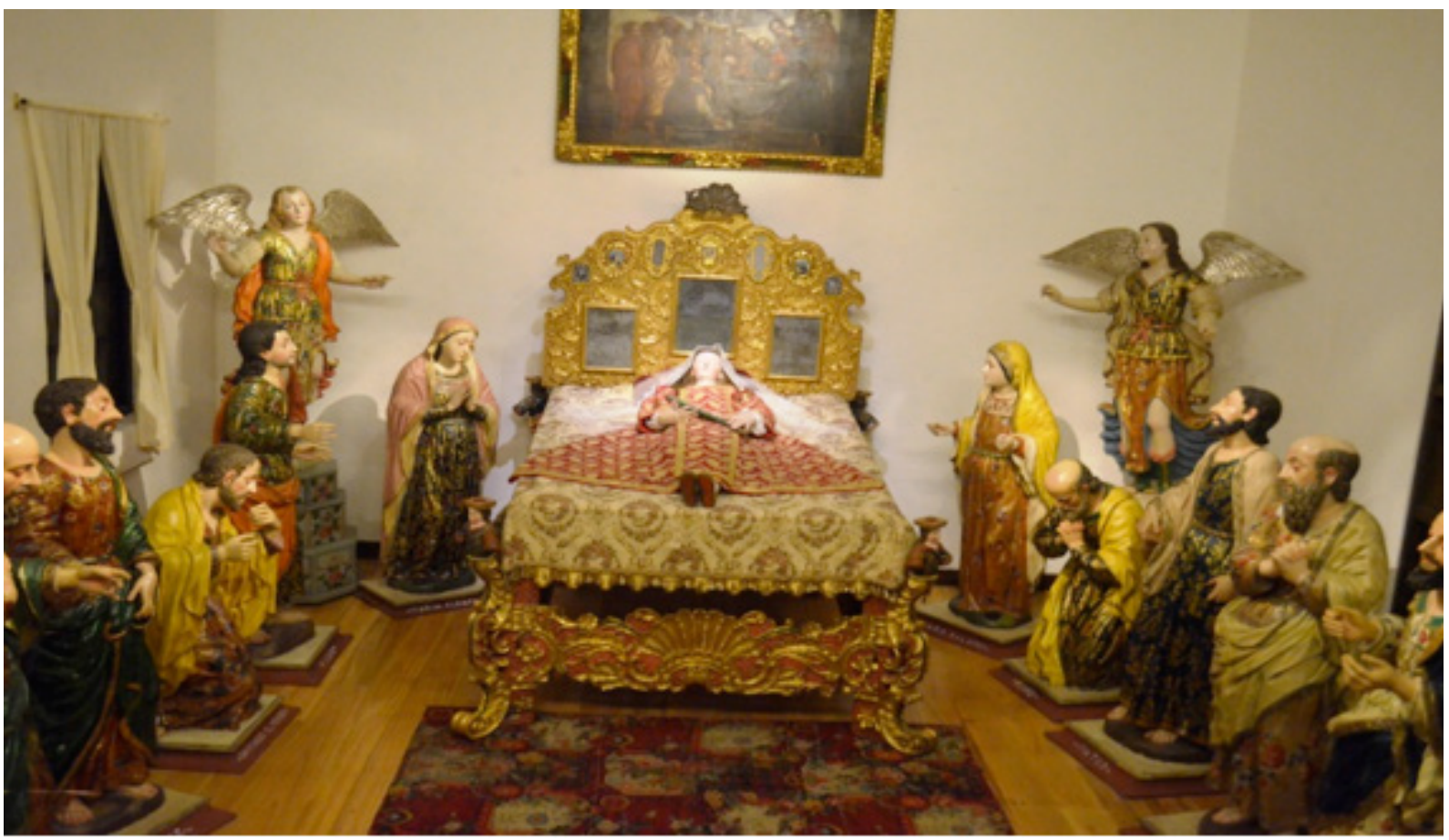

Fuente: Guía del Museo del Carmen Alto, http://es.scribd.com/doc/189535482/GUIA-DEL-MUSEO-DEL-CARMEN-ALTO\#scribd 
Figura No 5 Refectorio Museo del Carmen Alto.

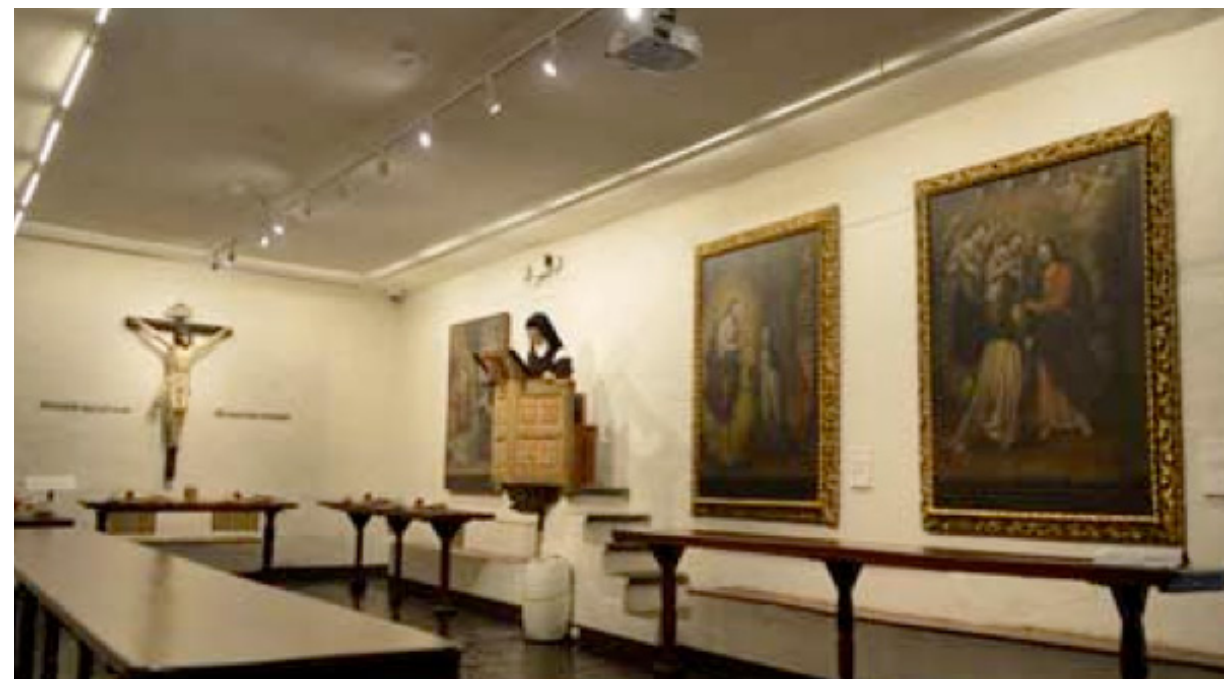

Fuente: Guía del Museo del Carmen Alto, http://es.scribd.com/doc/189535482/GUIA-DEL-MUSEO-DEL-CARMEN-ALTO\#scribd

Figura No 6 La Celda. Museo del Carmen Alto.

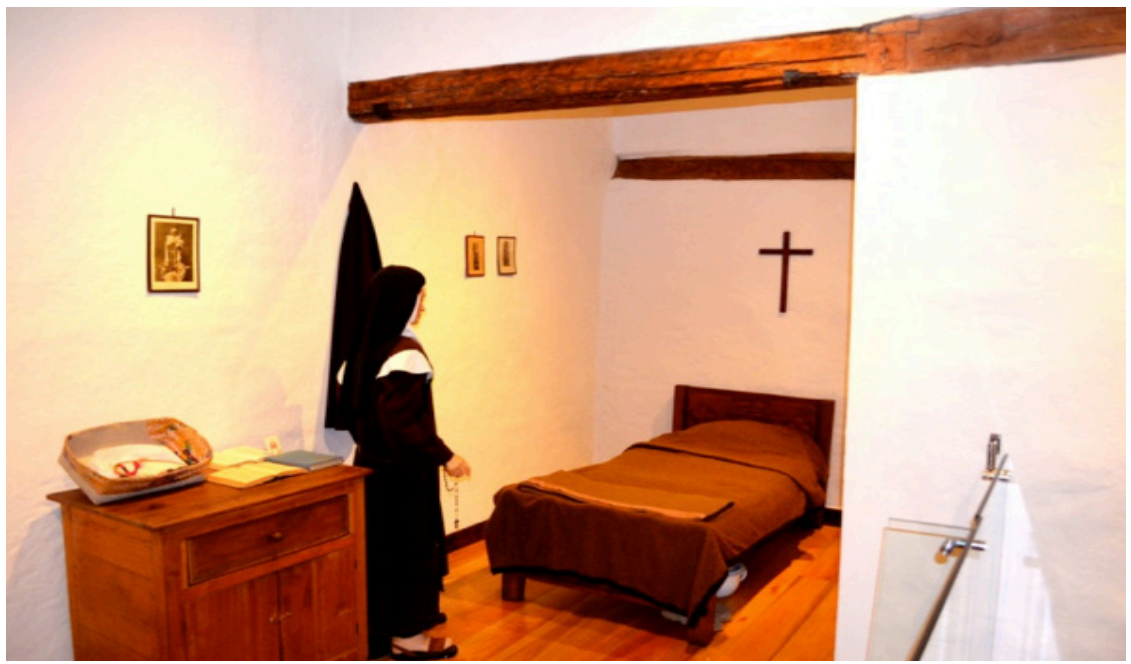

Fuente: Guía del Museo del Carmen Alto,

http://es.scribd.com/doc/189535482/GUIA-DEL-MUSEO-DEL-CARMEN-ALTO\#scribd 
Figura No 7 Conjunto Escultórico del Belén. Museo del Carmen Alto.

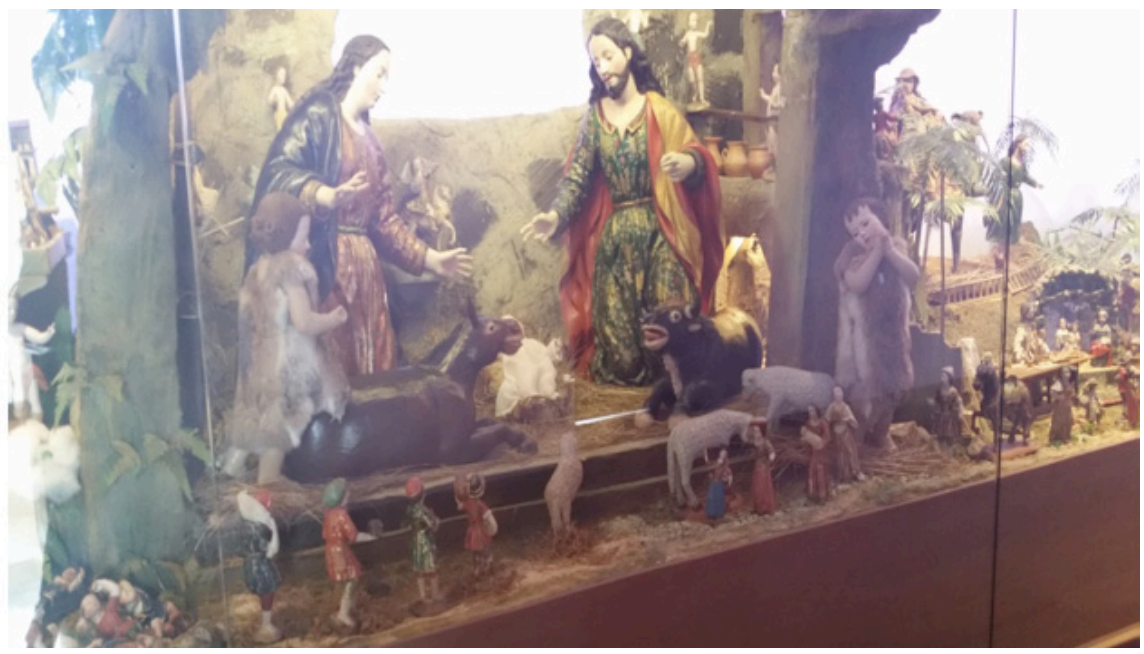

Fuente: Guía del Museo del Carmen Alto,

http://es.scribd.com/doc/189535482/GUIA-DEL-MUSEO-DEL-CARMEN-ALTO\#scribd

Figura No 8 Vihuela de Mariana de Jesús. Museo del Carmen Alto.

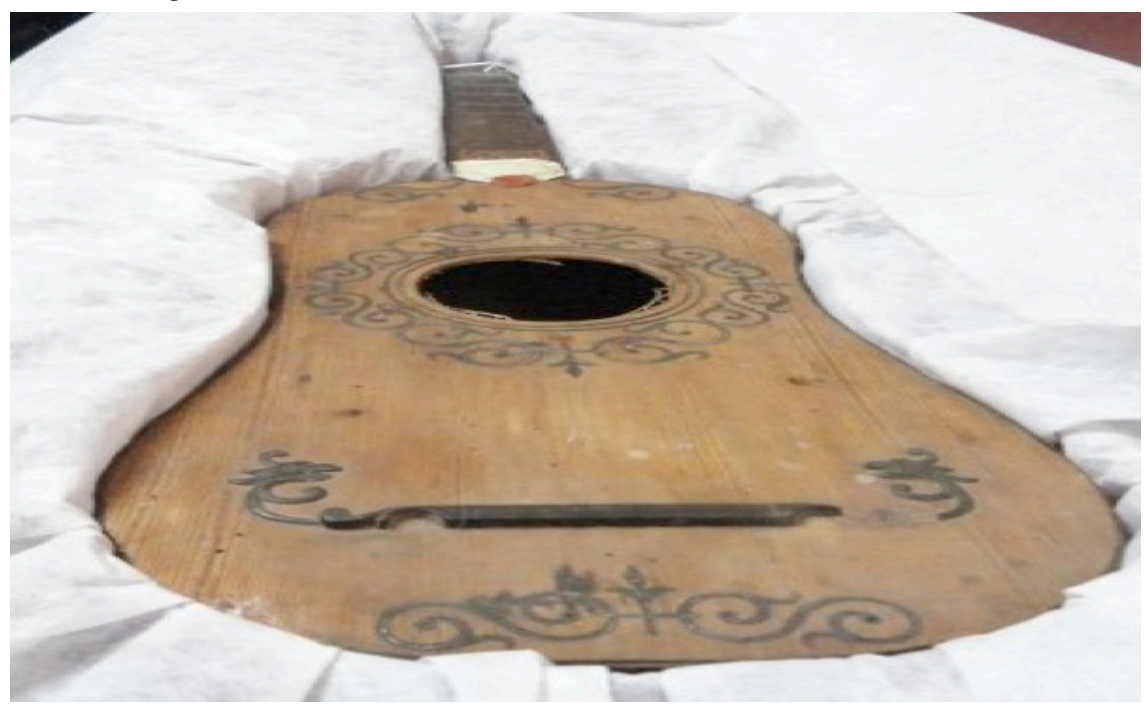

Fuente: Guía del Museo del Carmen Alto,

http://es.scribd.com/doc/189535482/GUIA-DEL-MUSEO-DEL-CARMEN-ALTO\#scribd 
Figura No. 9 Locutorio. Museo del Carmen Alto.

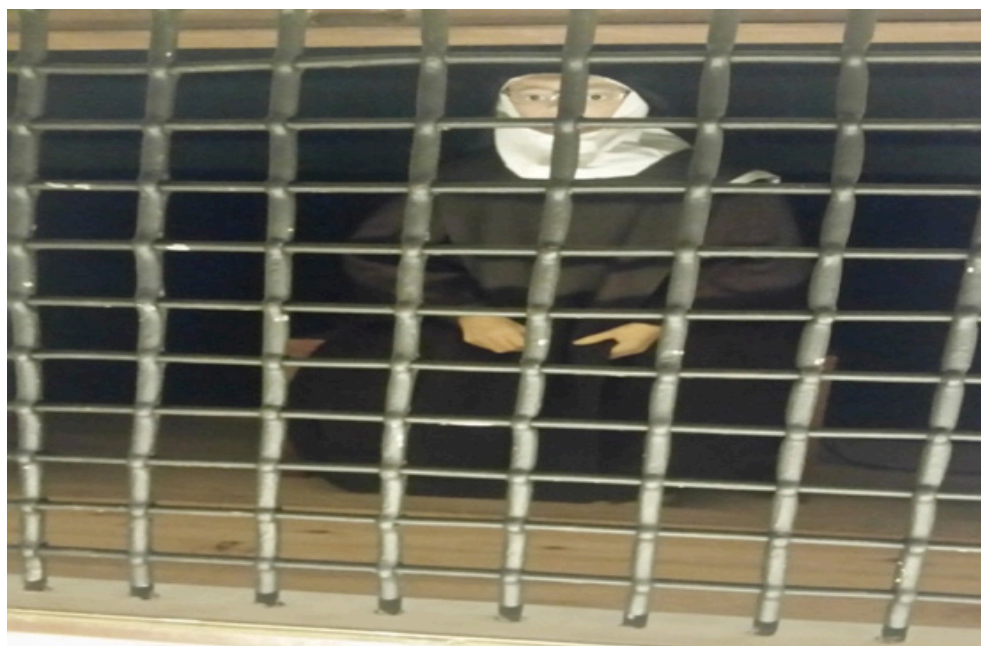

Fuente: Guía del Museo del Carmen Alto,

http://es.scribd.com/doc/189535482/GUIA-DEL-MUSEO-DEL-CARMEN-ALTO\#scribd

Figura No. 10 Portería Interna. Museo del Carmen Alto.

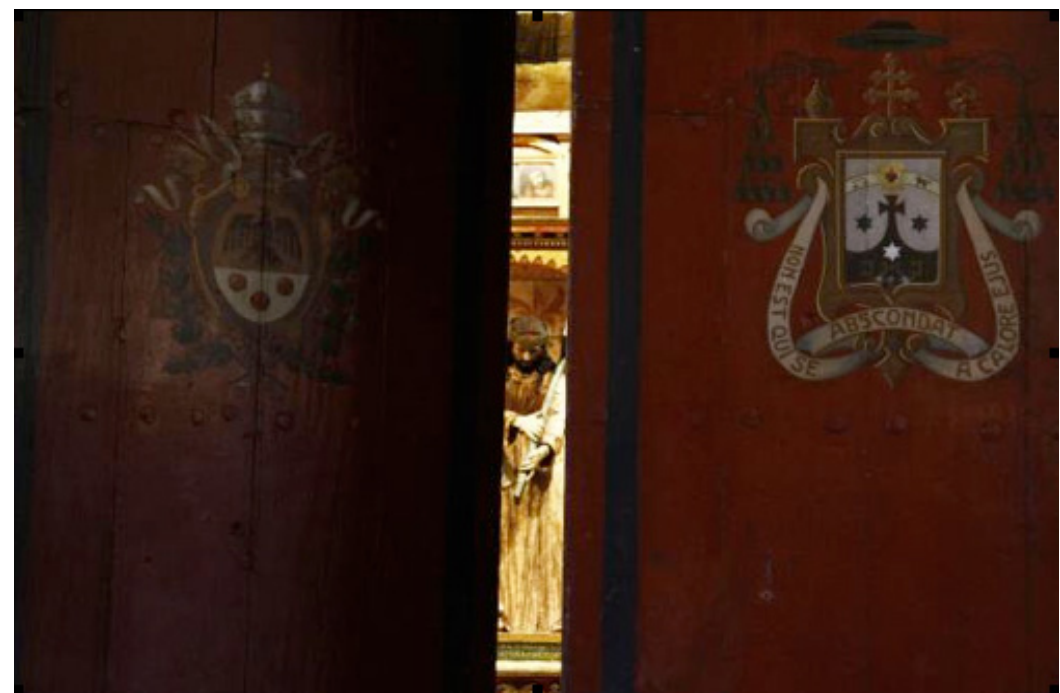

Fuente: Guía del Museo del Carmen Alto,

http://es.scribd.com/doc/189535482/GUIA-DEL-MUSEO-DEL-CARMEN-ALTO\#scribd 
Figura No. 11 Capilla. Museo del Carmen Alto.

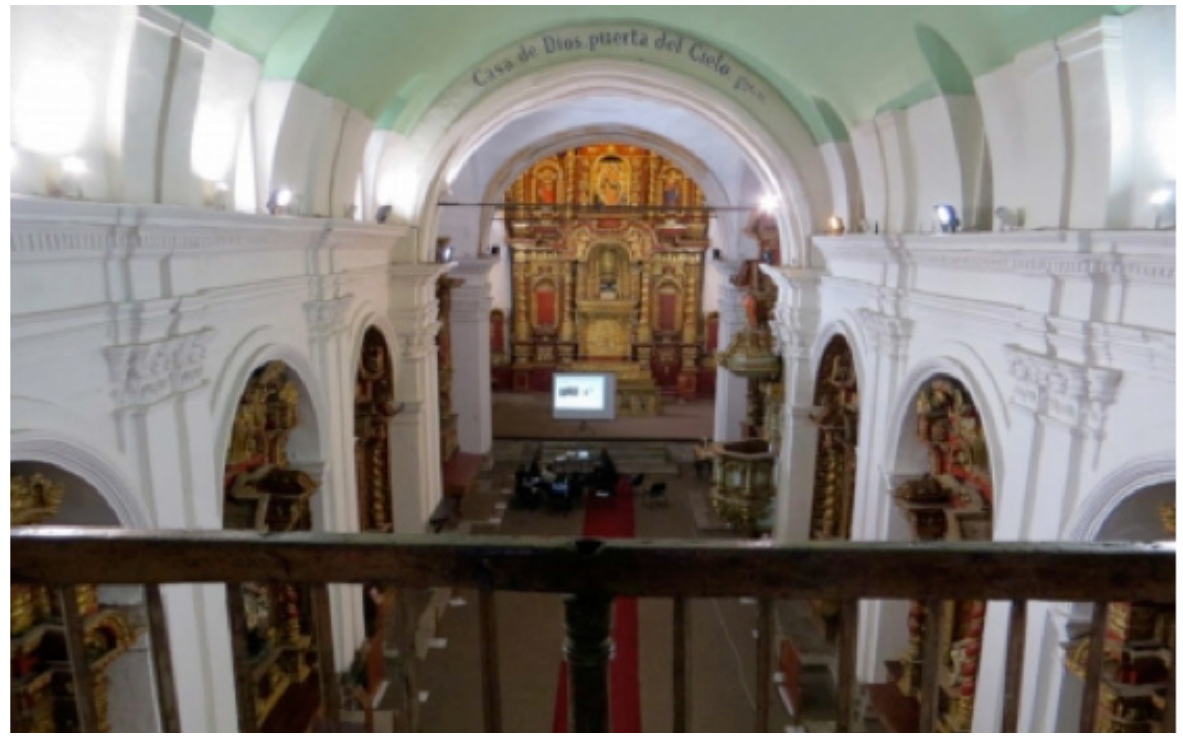

Fuente: Guía del Museo del Carmen Alto, http://es.scribd.com/doc/189535482/GUIA-DEL-MUSEO-DEL-CARMEN-ALTO\#scribd

Figura No. 12 Cocina. Museo del Carmen Alto.

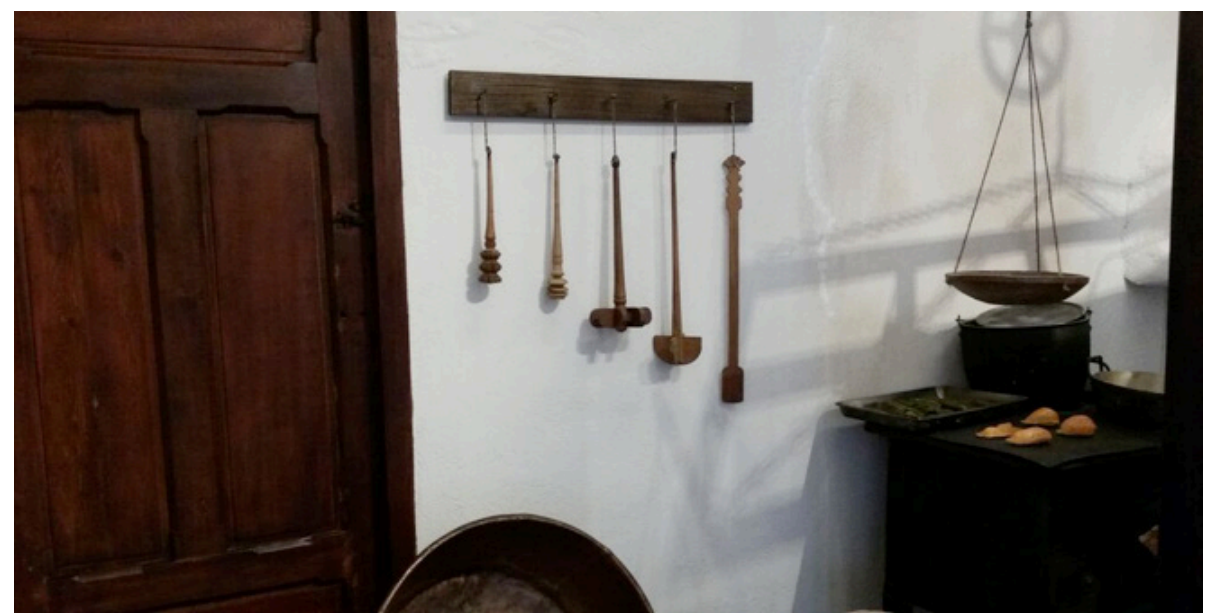

Fuente: Guía del Museo del Carmen Alto, http://es.scribd.com/doc/189535482/GUIA-DEL-MUSEO-DEL-CARMEN-ALTO\#scribd 
Uno de sus pintores principales es Víctor Mideros quien fue oriundo de San Antonio de Ibarra, reflejo su profunda religiosidad en sus pinturas, se le conoce como el "beata Laico" quiso transformar a Quito como la nueva Jerusalén. Es considerado como milenarista, místico, y su arte es conocido como "art nouveau" Kennedy, Alexandra (2002). En 1926 publicó 10 cuadros basados en la vida de la Beata Mariana de Jesús, hasta el año que publicó estas pinturas seguía siendo Beata recién en los 50's llega a ser Santa. Mideros pinta oleos que muestras las diferentes facetas de Mariana desde princesa hasta mártir, cabe aclarar que se la denomina princesa por que pertenecía a una familia aristócrata quiteña.

El arte es el sentimiento de la presencia universal de Dios. Y el cuadro, una palabra escrita con luces y sombras, formas y colores, animados con soplo de espíritu: una palabra mensajera que va en pos de dialogar con otra alma.

Cada color del Iris es una nota musical, un destello vital de ritmo planetario, un signo sugerente, una emoción solar. Cada color del Iris es un punto inicial en las realizaciones cósmicas de la luz, un mundo septiforme y espectral, una época distinta y milenaria. Cada color del Iris es aura milagrosa en la mística escala de las almas que buscan la claridad de Dios. Y el conjunto armónico de las Siete Cadencias o la Rosa cromática de los siete Esplendores suele ser imagen de un ciclo Esotérico" (Pérez, 1987).

Es en esta parte en donde el público visitante llega a preguntarse si se decide por los diferentes guiones teatralizados que ofrece el museo. Esta vez daremos un resumen del guion que Víctor Mideros teatralizará.

\section{Guión teatralizado del pintor "Víctor Mideros".}

Bienvenidos al Monasterio del Carmen antiguo de San José junto al Sr. Luis Ruiz somos profesores de la Escuela Nacional de Bellas Artes, he pintado en el testero de la Portería, el gran cuadro de la Virgen del Carmen, les ha complacido mucho a las monjitas ya que no es una Virgen seria, más bien tiene mirada maternal y cobija a las almas del Purgatorio bajo su manto.

Diez son los cuadros que dediqué a Santa Marianita de Jesús, con cierto orden cronológico, los guiaré. Sean Bienvenidos.

Doña María Grenoble Jaramillo, se encuentra levantando a Marianita hacia el cielo y la consagra a Dios, a su lado se encuentra su hija mayor doña Jerónima, que luego hará el papel de madre de Mariana. En la parte alta resplandece una estrella que apareció sobre la casa y en la parte de abajo se encuentra el demonio representado por un perro.

Víctor: ¿Que creen que significa el icono del perro? 
Visitante: ¿la tentación?

Víctor: justamente es así, le está embistiendo para que caiga Marianita.

Es de esta manera que con la interacción con el público se podrá ir desarrollando el guión.

Por ejemplo: ¿Uds. saben el voto que la virgen quiteña hizo a su ciudad con todo su amor? Aquí, ¿Podemos ver reflejado eso, ofreció su vida por su ciudad, su patria, es fácil notar su expresión de angustia, de amor, de súplica, aquí está pintada en sus aposentos, pero quién me puede decir en qué Iglesia nuestra, Santa hizo este ofrecimiento? Es una iglesia cercana de aquí.

Visitante: En la Iglesia la Compañía.

Víctor: ¿Quién sabe el nombre de este cerro que podemos apreciar en el cuadro?

Visitante: Es el Panecillo.

Víctor: ¿Saben otro nombre para este cerro? Bueno yo les cuento que también es conocido como Yavirac.

Si Uds. se dan cuenta, el espacio aquí es un reducido y por orden cronológico, hubiéramos puesto este cuadro antes del anterior, pero aproveché el lugar y he propuesto dejar aquí esta pintura, es la penitencia de Marianita, si pueden notar que es bien realista, cruda y un poco aterrante. Nuestra santa yace desmayada después de su disciplina de sangre.

En este cuadro podemos observar a Mariana con la vihuela y la acompañan tres ángeles.

Víctor: ¿Alguien tiene una idea que es la Vihuela?

Visitante: un instrumento musical.

Víctor: $\mathrm{Si}$, efectivamente, la vihuela es un instrumento musical muy parecido a la guitarra española de los siglos XVI y XVII, esta se encuentra como reliquia en el altar de nuestra señora de Loreto en la nave lateral izquierda de la Iglesia de la Compañía de Jesús. 
En el siguiente cuadro, podemos ver la crucifixión de Mariana de Jesús, la represento aquí en la semi claridad de una noche de luna, la luz penetrando por una ancha ventana que esta con rejas.

El Padre Morán de Buitrón quien escribió la hagiografía de Marianita de Jesús la describió así: "Tenía otra Cruz de estatura mediana, proporcionada a su cuerpo, y en las cuatro extremidades fortísimos cordeles de cerdas en forma de argollas, menos en la cabeza de la Cruz...todos los viernes del año cuando se hallaba con fuerzas, se crucificaba la Virgen Mariana de esta manera”.

Uds. se preguntarán por qué realizaba estos sacrificios y es que era tal la fe de nuestra Santa que meditaba de esta manera, con amor y ternura los tormentos de su Esposo, que era Jesús.

Visitante: ¿Qué es hagiografía?

Víctor: Es una obra literaria que relata la vida de los santos, este Padre Morán fue parte de la Orden Jesuita.

Pero como contraste, un hermoso contraste claro nos encontramos con este arte que nos brinda una representación de la ascensión luminosa.

Aquí ya no vemos sufrimiento, ni angustia, se terminó el dolor, las mortificaciones y penas, el alma de nuestra Marianita de Jesús aparece "transfigurada en su ascensión al cielo, personificando a la virgen prudente... ha sido llamada y sube con su lámpara encendida hacia el palacio celestial" Pólit (1926).

Junto a su amado esposo Jesús.

Entonces ya saben dónde estamos parados, aquí nació y murió nuestra Patrona, paisana! Se dan cuenta que suelo sagrado pisamos para todos los ecuatorianos! Aquí me despido yo! ¿Si recuerdan mi nombre?

Visitante: Si, Víctor Mideros.

Víctor: No me olviden, gracias por visitarme. 
Figura No 13 Pintura VIII Víctor Mideros "Cuando estuvieres airado, te acordarás de tu misericordia". Museo del Carmen Alto.

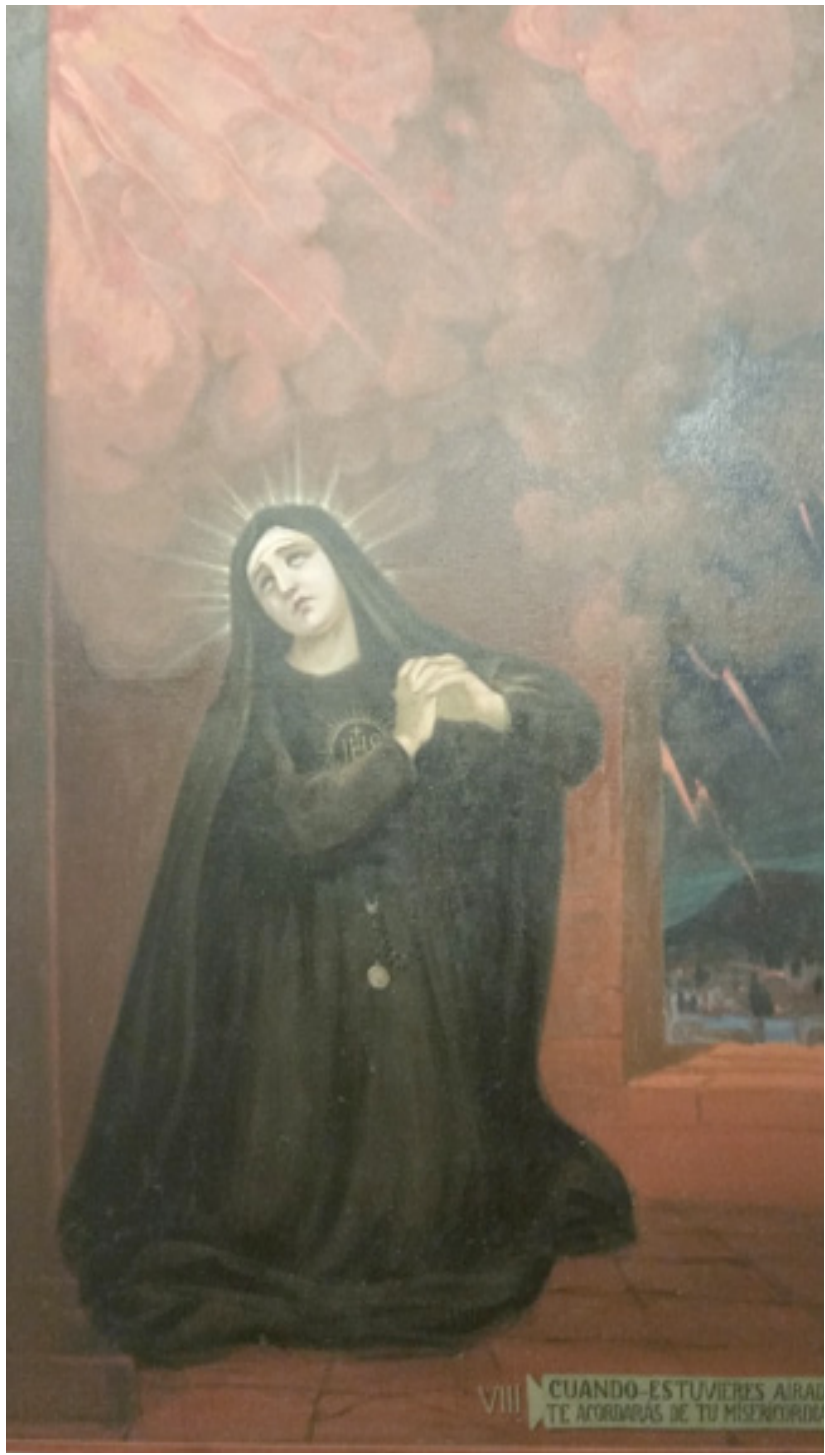

Fuente: Foto: María Belén Almeida Egas / Jesús Francisco González Alonso.
Figura No 14 Pintura IX Víctor Mideros "Acuérdate de tus postrimerías y no pecarás jamás”. Museo del Carmen Alto.

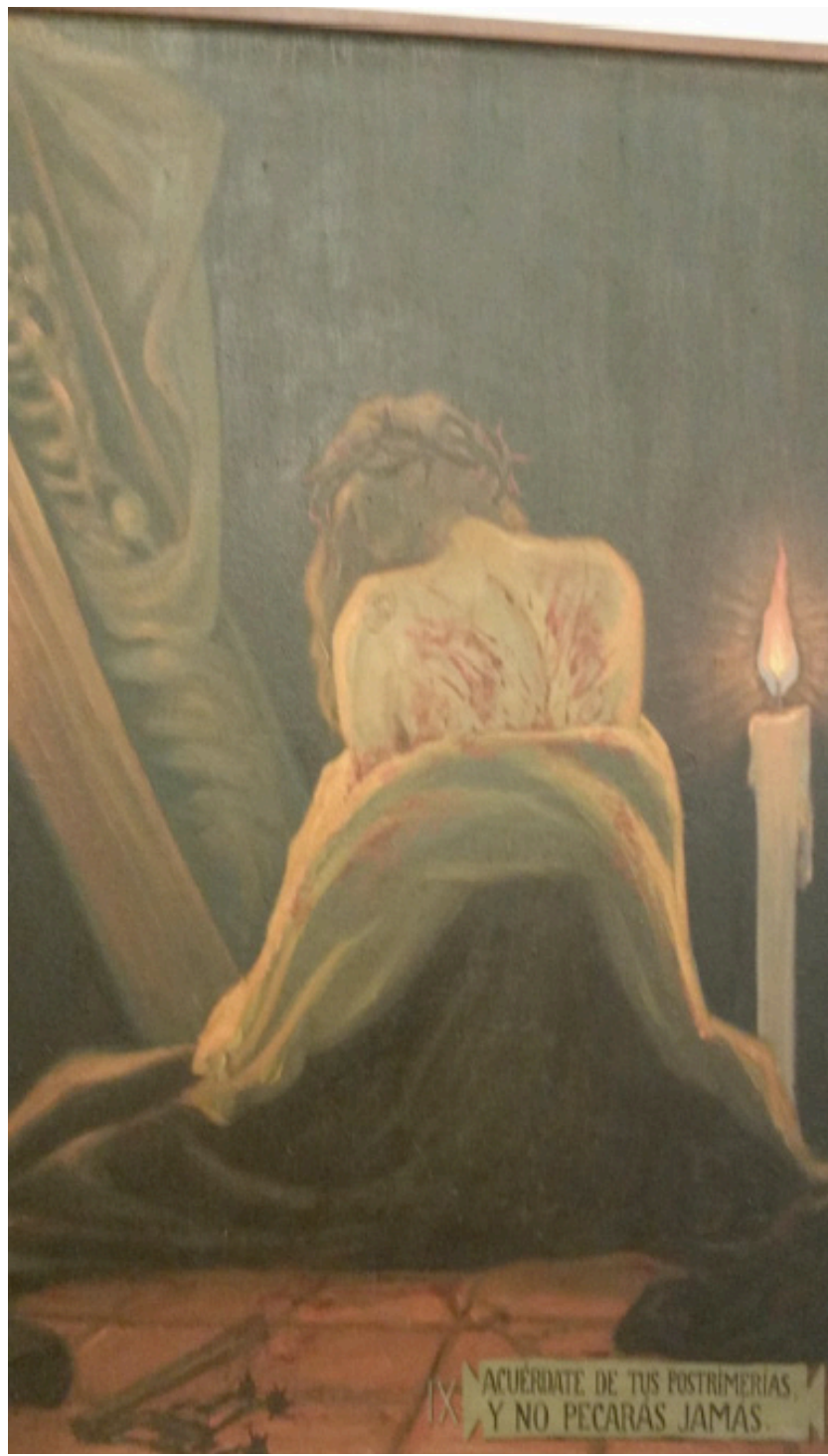

Fuente: Foto: María Belén Almeida Egas / Jesús Francisco González Alonso. 
Figura No. 15 Pintura VII Víctor Mideros "Y desde la eternidad vela por esta ciudad". Ascensión Luminosa de Santa Mariana de Jesús. Museo del Carmen Alto.

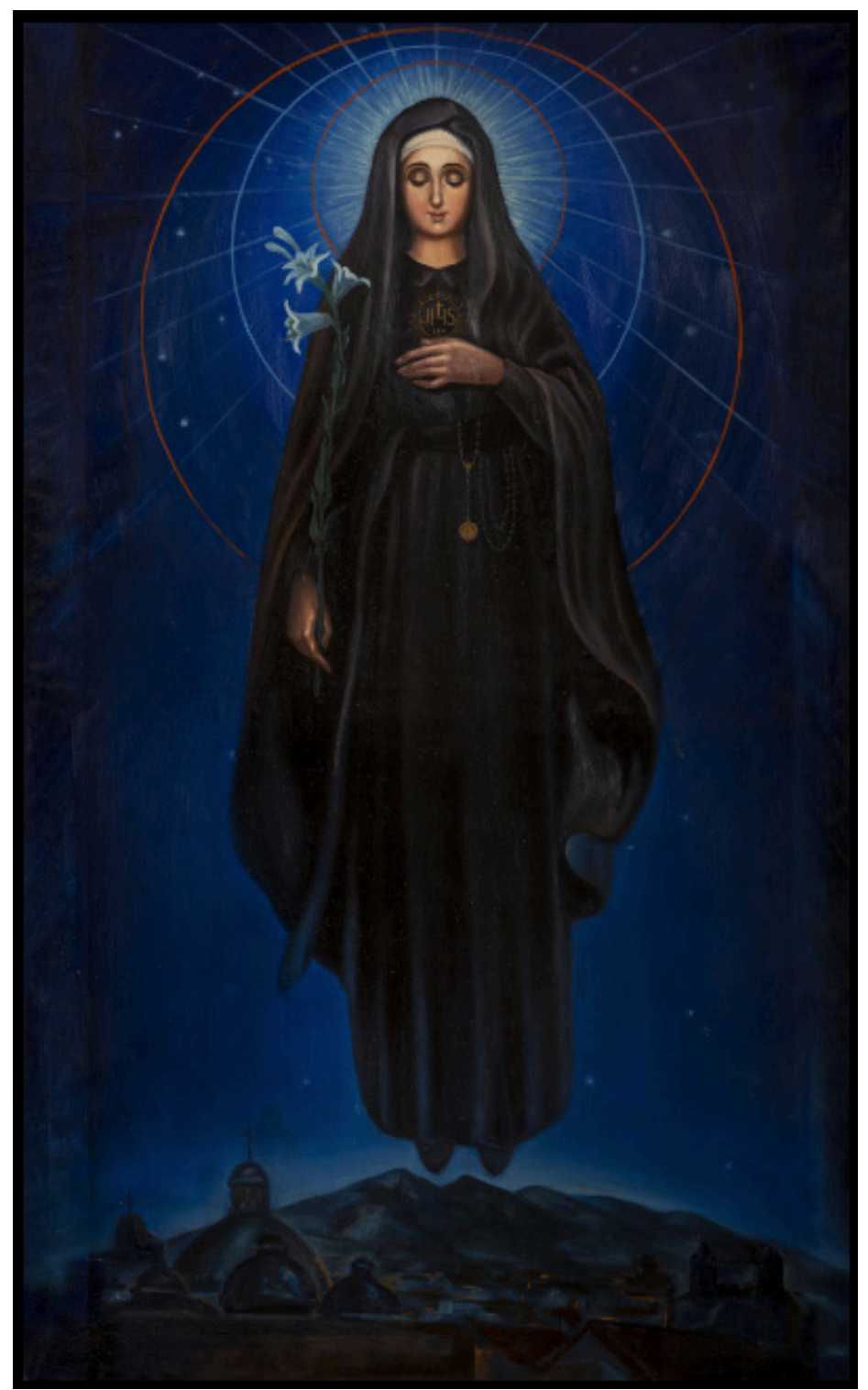

Fuente: Foto: María Belén Almeida Egas / Jesús Francisco González Alonso. 


\section{Guión teatralizado: "La vida cotidiana de la Orden de Carmelitas Descalzas".}

Buenos días, soy la Hermana Margarita de los Ángeles y voy a acompañarles en el recorrido.

Hermana: ¿Saben dónde estamos?

Visitante: en el museo del Carmen Alto.

Hermana: Sí, ¿alguién sabe de dónde viene el nombre de nuestra comunidad?

Visitante: Del Monte Carmelo.

Hermana: Efectivamente, quiero que nos ubiquemos en el siglo XII cuando unos ermitaños se quedaron en Israel, en el Monte Carmelo, y con el fin de seguir a Jesucristo, Nuestro Señor, adoptaron una vida de penitencia, oración y trabajo.

A mediados del siglo XIV, en España se fundan los primeros conventos de la Orden del Carmen, ahora tengo una pregunta, ¿alguién algunos de los jóvenes sabe la diferencia entre un monasterio y un convento? $\mathrm{O}$ ¿son sinónimos?

Visitante: el Convento es una casa como esta donde viven religiosos y el monasterio es más grande. Creo.

Hermana: Estas en lo correcto, el convento es un espacio religioso donde los clérigos llevan una vida que se rige a las órdenes de su santo Patrono, como ejemplo tenemos los: "franciscanos, carmelitas, dominicos, agustinos..."

Y los Monasterios son los conjuntos de edificios o espacios donde habitan monjes de una congregación religiosa. La diferencia entre un convento y un monasterio es que los Monasterios se construían en montañas, para que su vida sea netamente contemplativa. Ahora que sabemos la diferencia entre un convento y un monasterio, como les comenté hace un momento en España se fundan ya en el siglo XIV los primeros conventos de la Orden del Carmen, pero fueron ocupados por mujeres acaudaladas, luego con la reforma de Teresa de Jesús.

El rol de la mujer en la sociedad en el siglo XVI era difícil, tenían muchas barreras, el estado de la vida claustral prohibía el contacto de religiosas con el exterior.

Santa Teresa de Jesús es considerada como una de las primeras feministas, siempre 
perseguida por los inquisidores que siempre pensó que la mujer podía también ser oída y no solo oír.

Se determinó el número de religiosas para la congregación y siguiendo la Regla de Santa Teresa de Jesús serían veintiuna "dieciocho de velo negro que ingresarían con el aporte de dos mil pesos de dote y tres legas de velo blanco para el servicio; puso, igualmente, la cantidad de treinta y cuatro mil pesos en renta con la condición de reservar seis becas para admitir en el monasterio a mujeres de escasos recursos económicos que no pudieran pagar su dote" ¿Saben lo que es la dote? Pacheco, Adriana (2000).

Visitante: Creo que es una cantidad de dinero que se paga para entrar o cuando se casaban, el padre tenía que pagarle eso a su esposo.

Hermana: Según la Real Academia Española de la lengua dote es "congrua o patrimonio que se entrega al convento o a la orden en que va a tomar estado religioso una profesa".

Visitante: ¿Qué diferencia hay entre las monjas de velo blanco y velo negro?

Hermana: Que excelente pregunta, las hermanas de legas de velo blanco, trabajan para la comunidad en oficios domésticos y serviles. Puede ser en la cocina y la enfermería, como ejemplos.

Las hermanas de velo negro, generalmente pagaban la dote completa, ellas se dedican al oficio divino, al coro, a la vida contemplativa y la oración por la humanidad. Ahora sigamos con nuestro recorrido por la historia del Convento.

Las primeras monjitas Carmelitas vinieron a Quito en el año de 1653 el cuarto día de febrero desde Lima, entre estas cuatro monjitas se encontraba la Madre María de San Agustín quien era sobrina del Obispo Ugarte Saravia y era la priora fundadora del convento de Lima. Pacheco, Adriana (2000).

¿Se imaginan viajar por cuatro meses, cargadas por indígenas, transportadas por navíos en ríos sin explorar? Entonces quien recuerda queda como el día de conmemoración de la fundación del Carmen Alto en Quito?

Visitante: el 4 de febrero

Hermana: Correcto, que bueno que estén atentos, la vivienda perteneció a la familia de Mariana de Jesús Paredes y Flores. 
El Hermano Marcos Guerra Jesuita de la Compañía de Jesús, cumplió otra de las profecías de nuestra Santa Marianita.

Cabe recalcar que la mano de obra fue de mitayos de Zámbiza, Santa Prisca y Nayón hubieron albañiles, arrieros, canteros, carpinteros, herreros su salario era de tres pesos, al mes, dos reales se les pagaba y la comida era recibida diariamente.

Visitante: Hermanita una pregunta, ¿Y de que material está construido?

Hermana: esencialmente los materiales son arena, cangahua, chocoto y adobes utilizados en los patios.

Ahora sí que ya sabemos la historia de nuestro querido convento, les voy a contar de la vida en el claustro y su organización interna.

Nosotras alternamos el trabajo diario con la oración, antes se practicaba también la penitencia, nuestro día comienza muy temprano en la mañana, está repartido entre rezos, confección de obras manuales. Pasamos la vida, orando, trabajando y riendo. Entonces desde las cinco de la mañana es la levantada en donde agradecemos a nuestro señor Jesucristo por un hermoso nuevo día, las cinco y media es el laudes, a las seis de la mañana profesamos oraciones.

Luego tenemos eucaristía desde las siete hasta las ocho y al finalizar oramos la tercia, todo esto según las horas canónicas. A las ocho y media desayunamos y tenemos media hora, después es el trabajo, hasta las once y media que realizamos un examen de conciencia.

Desde las doce hasta la una de la tarde es nuestro almuerzo, luego viene la recreación que dura una hora. El retiro de Celda lo hacemos a las dos de la tarde, es nuestro santuario personal aquí permanecemos calladas.

Mariana se encuentra en el reclinatorio orando.

Hermana: Por favor hagamos silencio, es un lugar de oración, se dirige a los visitantes.

Mariana escucha y saluda a la hermana.

Mariana: Buenos Días, que alegría que nos estén visitando. Yo soy Mariana de Jesús, nací en el año 1618, aquí en Quito, desde los cuatro años quedé huérfana, pero quedé al cuidado y cariño de mi hermana mayor y su esposo. 
Mis sobrinas tienen casi mi misma edad, y siempre desde pequeñas, fuimos caritativas con los pobres, rezábamos el rosario y hacíamos el vía crucis.

Recibí el sacramento de la primera comunión cuando tenía ocho años.

Muchas veces quise ir a catequizar a la montaña, a un grupo de gente pagana que vivía allí, pero afortunadamente un toro nos devolvió a nuestras casas, entonces el esposo de mi hermana, se dió cuenta de mi amor por los pobres y mi deseo de oración y santidad, trató de que me recibieran en el convento de Santa Catalina, pero así no era como quería que fuera mi vida, se presentaron contrariedades y no llegue a formar parte de ninguna orden religiosa.

Pedí mi hermana que en su solar se construyera una habitación separada para poder tener una vida de meditación y retiro. Mi cuarto, muy sencillo, en donde medito también acerca de la muerte, me he conseguido un ataúd, algunas noches duermo ahí. Me he propuesto cumplir con el mandato de mi amado Jesús que dijo: "Quien desea seguirme que se niegue a sí mismo".

Hermana: Marianita, gracias por compartir un poco de tu vida, vamos a seguir el recorrido.

Mariana: Que Dios los guarde a todos.

Hermana: Marianita ha llegado al martirio corporal y es una de las expresiones máximas de su devoción religiosa. Sabe que prepara a su corazón para morada de nuestro amado Jesús, con diferentes penitencias, ayunos, martirios corporales con cilicios y coronas de espinas.

En una época hubo muchos terremotos, y una vez en la iglesia un padre jesuita dijo en un sermón:

- "Dios mío: yo te ofrezco mi vida para que se acaben los terremotos".

Pero Mariana exclamó: - "No, señor. La vida de este sacerdote es necesaria para salvar muchas almas. En cambio yo no soy necesaria. Te ofrezco mi vida para que cesen estos terremotos"

Mariana, fallece alrededor de las nueve y diez de la noche de un viernes 26 de mayo de 1645. Buitrón, Jacinto (1856). El 30 de noviembre de 1946, la Asamblea Nacional la declaró "Heroína Nacional", y el Papa Pio XII, el 9 de julio de 1950 declaró la santidad de Marianita de Jesús. 
Hermana: y ustedes. ¿Saben porque le dicen azucena de Quito?

Visitante: Porque en una de los patios de este monasterio, nació esta flor.

Hermana: Si, estás en lo correcto pero te falta agregar que la India Catalina que era una muchacha de la servidumbre, muy querida por Marianita, recogía las sangrías que ella muy feliz le daba a la Virgencita; es una de estas veces que ella ponía en el jardín su valiosa sangre y nace una bellísima azucena blanca. En el patio de los Naranjos podemos ver una representación donde nació esta flor.

Pero les sigo comentando como es nuestra vida cotidiana en medio de oraciones y alegrías.

A las tres de la tarde es la nona, que son alabanzas dura media hora, y luego tenemos lectura espiritual, que nos alimenta el alma. Luego trabajamos desde las cuatro y media hasta las seis de la tarde que nos encontramos para orar. A las siete de la noche son las vísperas, realizamos alabanzas en media hora todas vamos a la cena, luego desde las ocho hasta las nueve tenemos recreo, conversamos, nos reímos. Desde las nueve hasta las diez, realizamos las completas y hacemos oficio de lectura. Finalmente nuestro día se acaba a las diez, siempre contentas y agradecidas con la Virgen por cuidar de todos nosotros.

Acerca de nuestras fiestas principales es la de la devoción a la Virgen del Carmen, San José, y Santa Teresa de Jesús. Una de las penitencias más valiosas es la que realizamos desde el mes de septiembre, el día de la Exaltación de la Cruz y concluye en la Pascua de Resurrección. No comemos carne, huevos, ni derivados de la leche. Nosotros nos cubrimos con un velo, el locutorio era donde al principio recibíamos nuestras visitas, recuerdan donde están las pinturas del pintor Víctor Mideros? Ahí. Una reja protege la intimidad de la comunidad, la única persona que tiene la llave del locutorio como de la portería es la madre Priora.

Visitante: Ósea que, ¿nunca abren la puerta?

Hermana: La puerta de la clausura se abre en casos extremos, cuando viene un médico, o cuando entra el padre confesor.

Ahora entre los oficios tenemos que: los oficios como barrer, cocinar, ser ropera y provisora significa la entrega total al servicio hacia las hermanas. Los cargos de mayor responsabilidad son para las hermanas con más experiencia y sabiduría como por ejemplo: 
La sub-priora es la hermana encargada de dirigir el canto en el coro y el rezo.

Las clavarias, deben saber leer, contar y escribir. Y realizar el papel de la contabilidad.

La sacristana, es la encargada de la iglesia.

La receptora mayor/la portera (tornera), es la que tiene contacto con el mundo exterior a través del torno.

Las hermanitas celadoras, tienen un papel un poco más complicado, son las que vigilan las faltas de las otras hermanas y dan parte a la priora.

La de mayor responsabilidad es la Maestra de novicias, es la que vigila la formación espiritual de las futuras monjas, cuando era complicado para las mujeres aprender a leer, esta era la encargada de enseñar al resto de hermanas la lectura y escritura.

Ahora como Uds. saben la repostería de nuestro convento es famosa, ¿que han escuchado sobre que ofrecemos?

Visitante: Vino, hostias, dulces.

Hermana: Tenemos en dos habitaciones una pequeña fábrica de vino que se halla en un nivel más arriba del jardín. Las botellas de vino de consagrar las usan en los templos de Quito.

Pero no solo nos dedicamos a la comida también fabricamos productos aromáticos como: "fumariolas o "pastillas perfumantes", saumerio y "aguas olorosas" como el "agua de ámbar", de "azahar", "de ángeles", el "agua rica" y el "agua rosada"; el ingrediente principal de los compuestos era el aguardiente, al que añadían rosas, violetas, jazmines, flores de naranjo y especies como el clavo de olor, la canela y la nuez moscada." La priora actual del Convento es la madre Verónica de la Santa Faz. Pacheco, Adriana (2000).

Les voy a comentar que una antigua tradición religiosa de Quito es el coro del monasterio, "cantar es orar dos veces" la mejor conexión y señal de agradecimiento la podemos hacer de pie, de rodillas o en alabanza. Las monjitas profesas ósea, las de velo negro, podían formar parte del coro, en la época de la colonia el conocimiento del canto era bien valorado. Las que sabían cantar hasta podían exonerarse de la dote para ingresar al monasterio. Pacheco, Adriana (2000).

Hermana: ¿En qué idioma creen que cantaban? 
Visitante: ¿en español?

Hermana: no, en latín. La mayoría de cantos litúrgicos están escritos en esta lengua, por ende, las hermanas del coro tenían que aprender también este idioma.

Bueno, espero hayan disfrutado de aprender un poco de nuestra vida voy a seguir haciendo mi trabajo cotidiano. ¡Gracias a todos por su atención!

Figura No. 16 Patio interior "Los Naranjos", Hermanas desarrollando sus actividades. Museo del Carmen Alto.

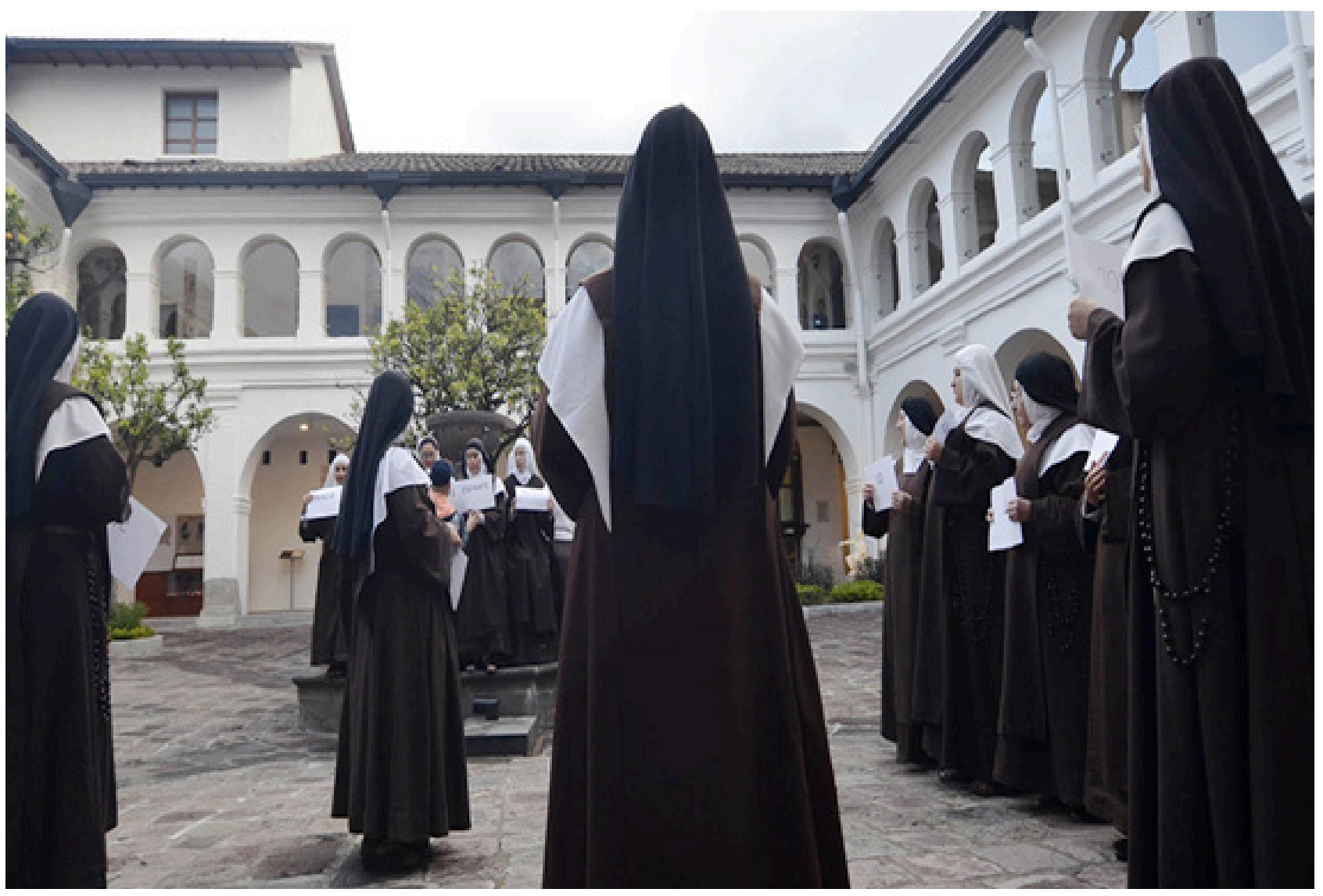

Fuente: Guía del Museo del Carmen Alto, http://es.scribd.com/doc/189535482/GUIA-DEL-MUSEO-DEL-CARMEN-ALTO\#scribd 
Figura No 17 Fábrica de Vino, Hermana desarrollando la actividad. Museo del Carmen Alto.

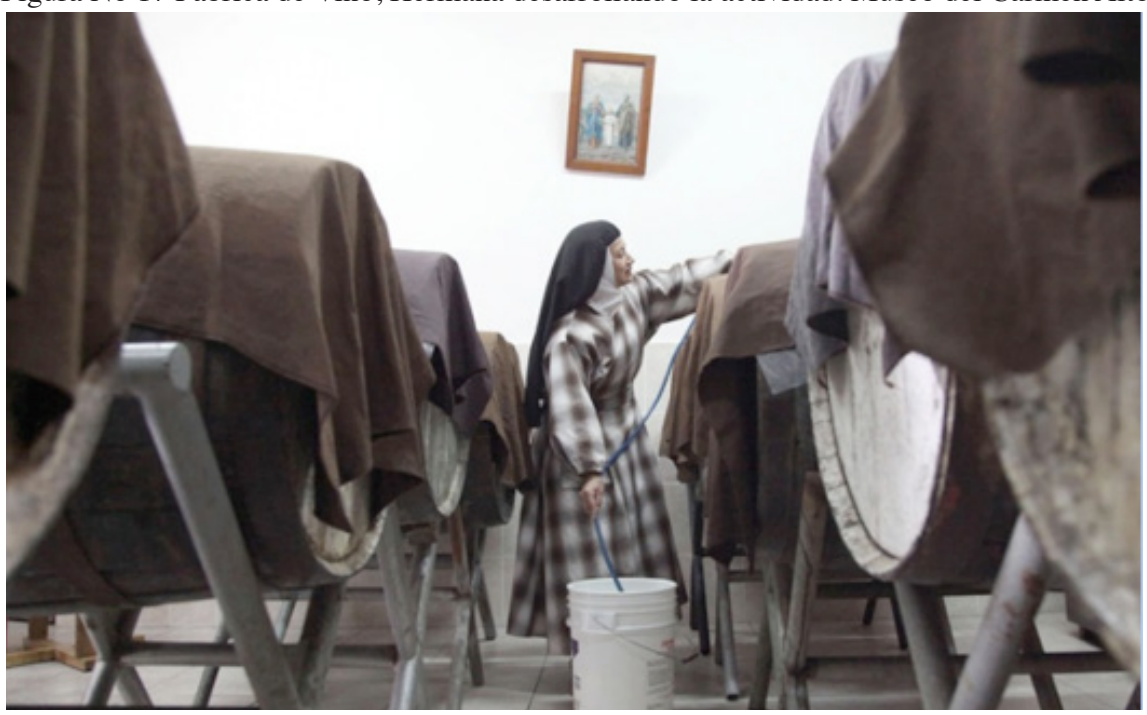

Fuente: Guía del Museo del Carmen Alto,

http://es.scribd.com/doc/189535482/GUIA-DEL-MUSEO-DEL-CARMEN-ALTO\#scribd

Figura No 18 Elaboración de hostias y majares, Hermanas desarrollando las actividades. Museo del Carmen Alto.

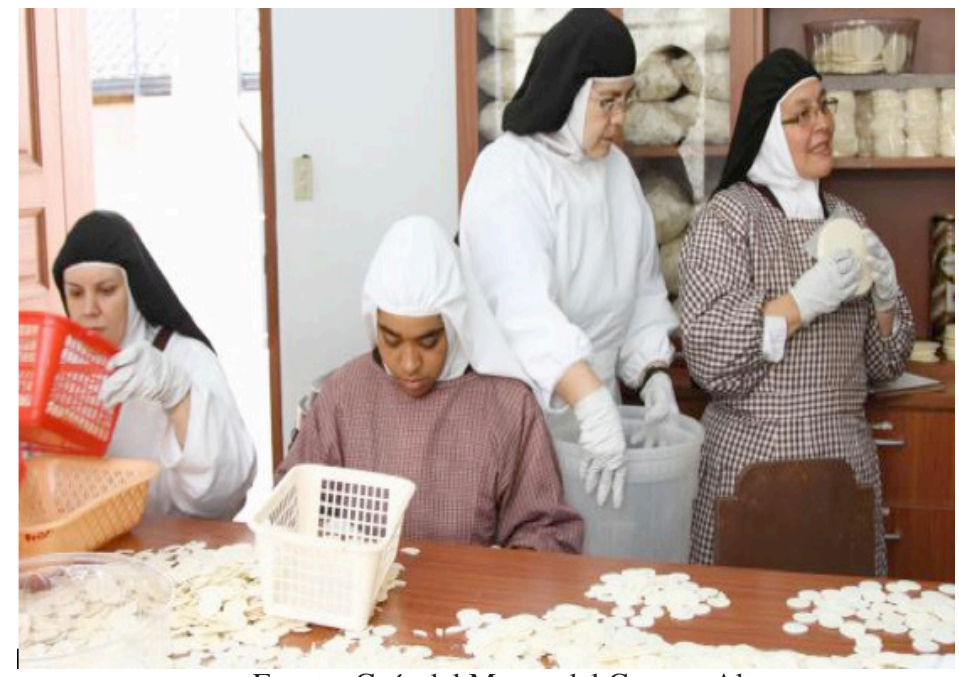

Fuente: Guía del Museo del Carmen Alto,

http://es.scribd.com/doc/189535482/GUIA-DEL-MUSEO-DEL-CARMEN-ALTO\#scribd 
Figura No. 19 Coro, Hermanas de la Orden del Carmen. Museo del Carmen Alto.

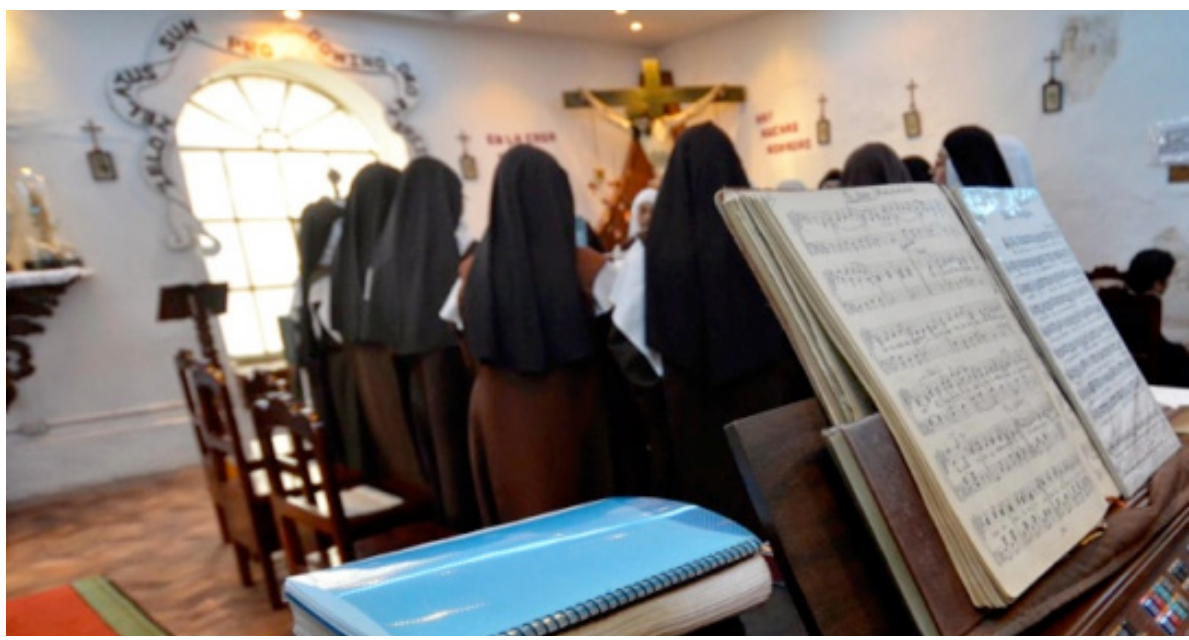

Fuente: Guía del Museo del Carmen Alto,

http://es.scribd.com/doc/189535482/GUIA-DEL-MUSEO-DEL-CARMEN-ALTO\#scribd

Figura No. 20 Interior del patio de Los Naranjos, Hermanas de la Orden del Carmen. Museo del Carmen Alto.

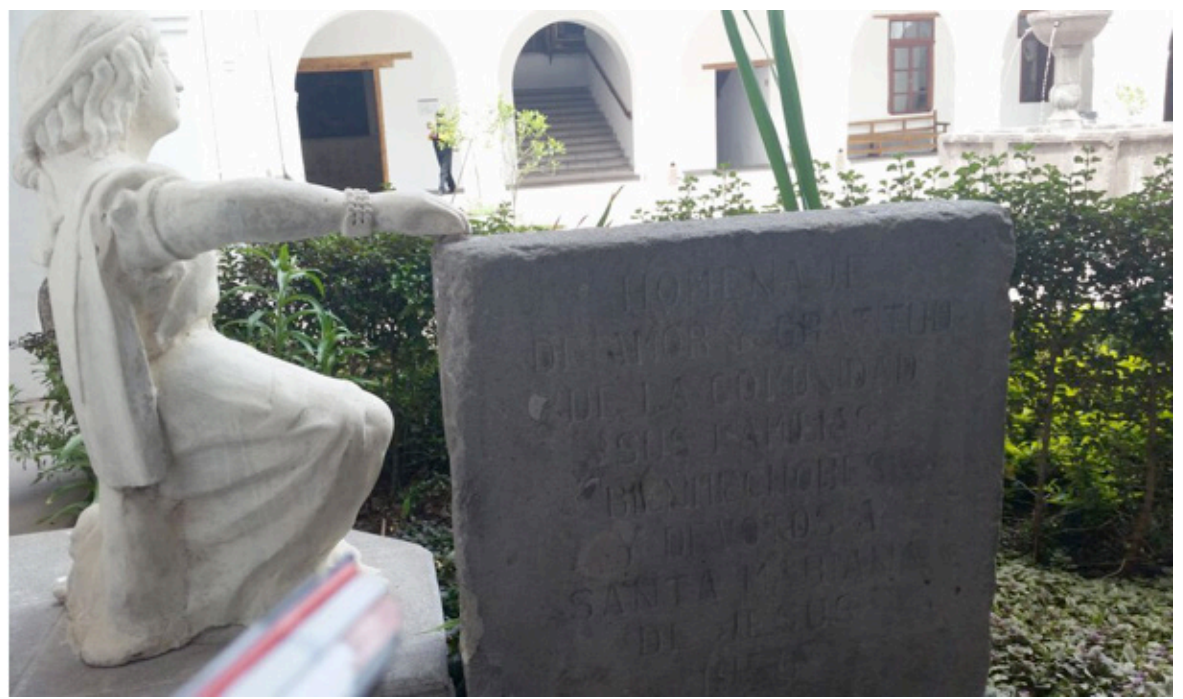

Fuente: Guía del Museo del Carmen Alto,

http://es.scribd.com/doc/189535482/GUIA-DEL-MUSEO-DEL-CARMEN-ALTO\#scribd 


\section{Conclusiones}

Mediante la aplicación de herramientas de educación y comunicación se ha constatado que los mediadores hacen los recorridos museológicos más interactivos con los visitantes. Existe una evolución en el estudio de los museos y el sistema educativo, la educación se convierte en "no formal" y se basa en las experiencias que se adquieren en los recorridos mediados.

Cabe recalcar que la comunicación que se tiene con el visitante es primordial, el mejoramiento con estas nuevas herramientas edu-comunicacionales, permite que el público que visita al museo sienta más atracción al turismo religioso y así se puedan estrechar vínculos generando experiencias.

El guión teatralizado capta la afluencia de turistas al museo ya que se basa en diálogos mantenidos con el visitante, siempre promoviendo el intercambio de saberes, experiencias. Así, el público se desenvuelve como actores participativos dentro de todos los recorridos. 


\section{Bibliografía}

ALBORNOZ Ximena, \& VARGAS José María. (2000). Historia Critica del Arte Hispanoamericano Real Audiencia de Quito (Siglos XVI, XVII, XVIII). Segunda edición. Editorial Abya Yala. Ecuador.

HOLGUÍN, María Cristina \& BAQUERO María Jesús. (2007). Educar: aprender y compartir en museos; memoria CECA Argentina. Primera Edición. Editorial Teseo. Argentina.

KENNEDY, Alexandra. (2002). Arte de la Real Audiencia de Quito, siglos XVII-XIX. Segunda edición. Editorial Nerea. Ecuador.

PACHECO, Adriana. (2000). Historia del Convento del Carmen Alto. Primera edición. Primera edición. Editorial Abya yala. Ecuador.

PERALTA, Evelia \&MOYA, Rolando. (2007). Guía Arquitectónica de Quito. Primera edición. Editorial Trama. Ecuador.

PICAZO, Carlos. (2011). Asistencia y Guía a grupos turísticos. Tercera edición. Editorial Síntesis. Colombia.

SABELLI, María. (2012). Museo como lugar de enseñanza. Primera edición. Editorial de la Torre. España.

VAQUERO, Alejandra. (2013). Historia de la Arquitectura III. Primera edición. Editorial Abya Yala. Ecuador.

VARGAS, José María. (2005). Historia de la Cultura Ecuatoriana. Primera edición. Editorial Abya Yala. Ecuador.

GÁNDARA Vázquez Manuel. (2010). Interacción e interactividad: Manual de Museografía Interactiva.

KENNEDY, Alexandra (1999). Construir la Nación Valoración y conservación del patrimonio ecuatoriano. Historia, arquitectura y comunidad. El caso de Cuenca." en: Estudios de Historia del Arte. Procesos Revista Ecuatoriana de Historia 25. Universidad Andina Simón Bolívar, Quito. Recuperado de http://alexandrakennedy-troya.weebly.com/artiacuteculos.html

KENNEDY, Alexandra. \& NÚÑEZ, Jorge. (2002). Quito, imágenes e imagineros coloniales. Antología de Historia, Quito: Flacso. Recuperado de http://alexandrakennedy-troya.weebly.com/artiacuteculos.html 
